\title{
Exchange transfusion of a patient with fulminant Lassa fever
}

\author{
David Cummins ${ }^{1,2}$, Diane Bennett ${ }^{2}$ and Samuel J. Machin ${ }^{1}$ \\ ${ }^{1}$ Department of Haematology, University College and Middlesex School of Medicine, London, UK and \\ ${ }^{2}$ Nixon Memorial Hospital and Lassa Fever Research Project, Sierra Leone, West Africa
}

\begin{abstract}
Summary: We report a patient with fulminant Lassa fever who responded dramatically to a 2.5-litre exchange transfusion of whole blood. On admission he was semicomatose with facial oedema and oral haemorrhage; his platelets showed markedly depressed aggregation to ADP; and his plasma inhibited the aggregation responses of normal platelets in vitro. Exchange transfusion resulted in rapid clinical improvement, recovery of platelet function, and disappearance of platelet-inhibitory activity in plasma. The patient died 2 weeks later from an acute encephalopathy. His initial response was sufficiently impressive to suggest that further evaluation of this therapeutic approach is justified in selected patients with overwhelming Lassa virus infection.
\end{abstract}

\section{Introduction}

Lassa fever is an acute arenavirus infection endemic in West Africa. ${ }^{1}$ Ribavarin is effective treatment for the disease if commenced within 6 days of the onset of fever. ${ }^{2}$ The prognosis for patients who present late in their illness is poor: despite antiviral therapy they may develop facial oedema, haemorrhage and shock, and the fatality rate in such cases exceeds $90 \%$. $^{1,2}$

The pathogenesis of severe Lassa fever is believed to involve disturbed cellular function rather than direct virus-induced cellular damage. ${ }^{3}$ Recent studies have shown that plasma from patients with severe Lassa virus infection exerts potent inhibitory effects on the function of normal platelets ${ }^{4}$ and normal neutrophils ${ }^{5}$ in vitro. These findings suggested a possible role for some form of plasma exchange therapy. We report a patient with Lassa fever who received a 2.5 -litre exchange transfusion of whole blood.

\section{Case report}

A 20 year old African man $(54 \mathrm{~kg})$ was admitted to a hospital in eastern Sierra Leone with a 2-week history of fever, dry cough and headache, and a 3-day history of gingival haemorrhage. On examination he was semicomatose and had marked facial oedema. His oral temperature was $38.5^{\circ} \mathrm{C}$, pulse

Correspondence: D. Cummins, M.D., M.R.C.P., M.R.C.Path., Department of Haematology, Middlesex Hospital, London W1, UK.

Accepted: 20 September 1990
$124 / \mathrm{min}$ and blood pressure $120 / 80 \mathrm{mmHg}$. Apart from mild pharyngitis there were no other abnormal signs.

The packed cell volume was $32 \%$, white cell count $27.5 \times 10^{9} / 1 \quad(90 \%$ neutrophils $)$, platelet count $110 \times 10^{9} / 1$ and serum aspartate aminotransferase (AST) $8032 \mathrm{IU} / 1$ (normal < $45 \mathrm{IU} / \mathrm{l}$ ). His serum contained IgG and IgM antibodies to Lassa virus at titres of $\geqslant 1024$ and $\geqslant 16$, respectively. Platelet aggregation studies showed markedly depressed responses to ADP, with rapid and complete disaggregation evident at final ADP concentrations up to $10 \mu \mathrm{mol} / 1$. His plasma inhibited ${ }^{4}$ the ADP-induced responses of normal platelets in vitro.

He was commenced on intravenous ribavarin (100 mg/ $\mathrm{kg}$ loading dose and $25 \mathrm{mg} / \mathrm{kg}$ daily in three divided doses for 3 days, then $12.5 \mathrm{mg} / \mathrm{kg}$ for the next 7 days $^{2}$ ) but over the next few hours he became increasingly drowsy and had two grandmal fits. This deterioration, and the presence of several poor-prognosis indicators, ${ }^{1,2}$ prompted consideration of plasma exchange therapy. As no facilities for whole-blood centrifugation were available, a simple exchange transfusion was undertaken.

The patient was placed in a small isolation cubicle and his attendant medical staff were provided with disposable gloves, paper masks and gowns. Chloroquine was given subcutaneously for malarial prophylaxis. Five pints of fresh, ABOcompatible blood were obtained, one from his father and four from unrelated local people (none had Lassa virus antibodies detectable in serum). Over a 24-hour period, a 5-unit exchange transfusion was performed. 
During the exchange the patient remained semiconscious and unresponsive to verbal commands. Twenty-four hours after the procedure, however, his conscious level had improved, there was no fresh haemorrhage occurring from his mouth, and his facial oedema was less marked. His serum AST level had fallen to $2375 \mathrm{IU} / 1$, his platelets showed improved aggregation responses to ADP, and his plasma showed no platelet-inhibitory activity. Over the next few days he became conversant with his attendants and began to eat and drink. Six days after admission he was apyrexial and his platelets showed normal ADP-induced aggregation responses. Thirteen days after admission he was eating well and walking unaided, his white cell count was $6 \times 10^{9} / 1$ and his serum AST $100 \mathrm{IU} / 1$.

However, on the day of his intended discharge from hospital he was found in a state of stupor. He was drowsy but responded to painful stimuli. A diffuse, fine tremor was evident, most marked in the upper limbs, and he had mild left-sided weakness. Reflexes were generally depressed, the plantar responses extensor. His blood sugar was normal and malarial parasites were absent from blood smears. Acute post-viral encephalopathy was diagnosed. Over the next 48 hours his conscious level deteriorated and he developed a chest infection. Despite intensive nursing care, intravenous fluids and antibiotics, he died. An autopsy was refused.

\section{Discussion}

This patient had life-threatening Lassa fever and deteriorated despite antiviral treatment. Although transfusion of blood in West Africa poses several major hazards, it was felt that his prognosis was sufficiently grave to justify some form of plasma exchange therapy. The exchange procedure was followed by a dramatic clinical improvement, cessation of haemorrhage, recovery of platelet function, and disappearance of platelet-inhibitory act- ivity in plasma. Such a rapid recovery from Lassa fever of this severity is exceptional, and it may therefore have been directly related to the exchange transfusion; however, the mode of therapeutic benefit is not clear. Unfortunately, the patient died 2 weeks later from an acute encephalopathy, a complication of Lassa fever which is currently ill-understood. ${ }^{1}$

The rationale for performing the exchange was based on the findings of our recent studies which showed that plasma from patients with severe of Lassa fever profoundly inhibits the function of $\overrightarrow{0}$ normal platelets and normal neutrophils in vitro.,5 The nature of the inhibitory factor has not yet been defined, but it appears to be neither virus nor virus antibody since the inhibitory phenomenon cannot be reproduced by supernatants from Lassa-virusinfected tissue cultures, nor by concentrated IgG fraction from convalescent serum. ${ }^{4}$

To our knowledge, no form of plasma exchange therapy has previously been attempted in a patient with Lassa fever. However, infusions of convalescent, immune plasma have been employed, with variable success. ${ }^{2,6,7}$ Since it is now clear that plasma from convalescent Lassa fever patients does not contain significant amounts of neutralizing antibody, ${ }^{2}$ any apparent benefit from its use is unlikely to have been due to direct antivira activity. An infusion of non-Lassa-immune plasm has also been reported, in a single case, to have bee] associated with a favourable outcome. ${ }^{8}$ However, there has been too little experience with plasma infusions, both immune and non-immune, to assess the possible efficacy of such therapy in patients with fulminant Lassa fever. The dramatic response shown initially by our patient suggests that further evaluation of this therapeutic approach is justified.

\section{Acknowledgements}

Dr David Cummins was supported by Schering Health Care and a grant from the Wellcome Trust.

\section{References}

1. McCormick, J.B., King, I.J., Webb, P.A. et al. A case-control study of the clinical diagnosis and course of Lassa fever. $J$ Infect Dis 1987, 155: 445-455.

2. McCormick, J.B., King, I.J., Webb, P.A. et al. Lassa fever: effective therapy with ribavarin. $N$ Engl $J$ Med 1986, 314: 20-26.

3. Walker, D.H., McCormick, J.B., Johnson, K.M. et al. Pathologic and virologic study of Lassa fever in man. Am J Pathol 1982, 107: 349-356.

4. Cummins, D., Fisher-Hoch, S.P., Walshe, K.J. et al. A plasma inhibitor of platelet aggregation in patients with Lassa fever. Br J Haematol 1989, 72: 541-548.

5. Roberts, P.J., Cummins, D., Bainton, A.L. et al. Plasma from patients with severe Lassa fever profoundly modulates f-metleu-phe-induced superoxide generation in neutrophils. $\mathrm{Br} J$ Haematol 1989, 73: 152-157.
6. Leifer, E., Gocke, D.J. \& Bourne, H. Report of a new virus disease of man from West Africa. II. Report of a laboratoryacquired infection treated with plasma from a person recently recovered from the disease. Am J Trop Med Hyg 1970, 19: 677-679.

7. Frame, J.D., Verbrugge, G.P., Gill, R.G. \& Pinneo, L. The use of Lassa fever convalescent plasma in Nigeria. Transcr $R$ Soc Trop Med Hyg 1984, 78: 319-324.

8. Fisher-Hoch, S.P., Craven, R.B., Forthall, D.N. et al. Safe intensive-care management of a severe case of Lassa fever with simple barrier nursing techniques. Lancet 1985, ii: 1227-1229. 